\title{
ANALISIS PENGARUH BRAND AWARENESS, BRAND LOYALTY DAN HARGA TERHADAP KEPUASAN PELANGGAN PT. JICO AGUNG JAKARTA
}

\author{
${ }^{1}$ Estu Mahanani, ${ }^{2}$ Bida Sari \\ ${ }^{1,2}$ Universitas Persada Indonesia Y.A.I. \\ J1. Pangeran Diponegoro No.74 Jakarta, Indonesia-10340 \\ ice2mahanani@gmail.com
}

\begin{abstract}
This study aims to determine the effect of brand awareness (X1), brand loyalty (X2) and price (X3) on Customer Satisfaction (Y). The method used is the interactive-associative research. This research population is all of the PT. Jico Agung's customer in East Jakarta. The sampling technique is done by purposive sampling with certain criteria. The sample of the research are 30 respondents (PT. Jico Agung's customer who live in RT.013 and 014, RW.07, North Utan Kayu, East Jakarta. Data collection is using observation, interviews and questionnaires. Analysis of the data used is quantitative analysis, including correlation analysis, determination analysis and multiple linear regression analysis (simultaneously), and hypothesis testing using t-test and F-test. The results of data processing performed with SPSS 25.0 for windows. The value of correlation coefficient $(\mathrm{R})$ is 0,848 . The value of determination coefficient $\left(\mathrm{R}^{2}\right)$ is 0,687 . It means that $68,7 \%$ variation of dependent variable (Customer Satisfaction) could be predicted from the combination of variables (brand awareness, brand loyalty and price) and the remaining $31,3 \%$ is influenced by other factors. The regression equation was obtained $\hat{\mathrm{Y}}=0,26+0,360 \mathrm{X} 1+0,397 \mathrm{X} 2+$ $0,234 \mathrm{X} 3$. For the $\mathrm{F}$ test obtained $\mathrm{F}$ value is calculated at 22.266 , greater than F-table $(2,98)$ with $\alpha=5 \%$, so the conclusion: reject $\mathrm{Ho}$ and $\mathrm{Ha}$ is accepted. It means there is significant influence of brand awareness (X1), brand loyalty (X2) and price (X3) together on Customer Satisfaction (Y).
\end{abstract}

Keywords: Brand Awareness, Brand Loyalty, Price, Customer Satisfaction

\section{PENDAHULUAN}

\subsection{Latar Belakang}

Persaingan bisnis yang ketat menuntut perusahaan menghasilkan produk berkualitas dan pelayanan prima. Demikian halnya dengan PT. Jico Agung, salah satu group Miwon di Indonesia, selalu berusaha menjawab kebutuhan konsumen dengan menghasilkan produk yang berkualitas PT. Jico Agung yang memfokuskan bidang usahanya pada distribusi atau perdagangan dalam negeri, merupakan anak perusahaan dari Daesang Corporation, Korea.

Seiring dengan kemajuan perusahaan serta perkembangan kebutuhan masyarakat di Indonesia, saat ini PT Jico Agung tidak hanya mendistribusikan produk-produk dari Miwon Indonesia melainkan juga produk-produk dari Daesang Group, Korea dan afiliasinya seperti minyak jagung, minyak kedelai, selai, dan lain-lain serta rokok yang diimpor langsung dari Korea. 
Ekuitas merek (brand equity) menarik untuk diteliti dan dijadikan dasar bagi seorang produsen atau perusahaan karena ekuitas merek memiliki nilai penting untuk menciptakan kepuasan konsumen sehingga dapat digunakan sebagai acuan produk private label dalam persaingan bisnis (Yunitasari dan Ahyar, 2006; Tjandrasa, 2006; Lee dan Fayrene, 2011; Bilal dan Faiza, 2014). Dimensi ekuitas merek yang berkualitas terdiri dari: asosiasi merek, persepsi kualitas, kesadaran merek (Brand Awareness) dan loyalitas merek (Brand Loyalty). Dimensidimensi tersebut dapat berpengaruh terhadap efektivitas strategi merek dimasa mendatang (Lee dan Fayrene, 2011). Kesadaran merek, persepsi kualitas, juga loyalitas merek merupakan bagian dari ekuitas merek yang dapat dijadikan alat ukur kepuasan konsumen (Yunitasari dan Ahyar, 2006; Bilal dan Faiza, 2014; Ahmad dan Najeeb, 2015; Siregar, 2016).

Kesadaran merek (Brand Awareness) adalah kesanggupan seorang calon pembeli untuk mengetahui atau mengingat kembali suatu bentuk, merek, simbol atau logo dari produk tersebut. Sedangkan loyalitas merek (brand loyalty) adalah keadaan komitmen dimana pelanggan memilih melanjutkan penggunaan dari merek atau membeli kembali merek yang sama.

Hal terpenting yang juga perlu diketahui konsumen di dalam proses konsumsi adalah besarnya harga jual yang ditetapkan oleh perusahaan baik produk maupun jasa. Kotler dan Amstrong (2009) mengatakan bahwa "Harga adalah jumlah uang yang dibebankan untuk sebuah produk atau jasa atau jumlah dari nilai yang ditukar konsumen atas manfaat-manfaat karena memiliki atau menggunakan produk atau jasa tersebut". Harga merupakan salah satu atribut penting yang dievaluasi oleh konsumen sehingga manajer perusahaan perlu benar-benar memahami peran tersebut dalam mempengaruhi sikap konsumen.

Perusahaan Jico Agung menentukan harga dengan relatif lebih murah dibandingkan pesaingnya PT. Ajinomoto, PT. Forisa dan lainnya untuk meningkatkan minat beli konsumen. Karena kunci utama perusahaan untuk memenangkan persaingan adalah dengan memberikan nilai dan kepuasan pelanggan melalui produk berkualitas dan harga yang bersaing.

Berdasarkan latar belakang masalah tersebut, peneliti tertarik untuk melakukan penelitian dengan judul "ANALISIS PENGARUH BRAND AWARENESS, BRAND LOYALTY DAN HARGA TERHADAP KEPUASAN PELANGGAN PT. JICO AGUNG JAKARTA".

\subsection{Perumusan Masalah}

Peneliti menetapkan satu masalah pokok penelitian yaitu: "Bagaimana cara mencapai kepuasan pelanggan PT. Jico Agung Jakarta melalui brand awareness, brand loyalty dan harga?".

\subsection{Tujuan Penelitian}

Penelitian ini bertujuan memberikan bukti empiris atas: 
1. Pengaruh brand awareness terhadap kepuasan pelanggan.

2. Pengaruh brand loyalty terhadap kepuasan pelanggan.

3. Pengaruh harga terhadap kepuasan pelanggan.

4. Untuk mengetahui dan menganalisis pengaruh brand awareness, brand loyalty dan harga secara bersama-sama terhadap kepuasan pelanggan.

\section{KAJIAN LITERATUR}

\subsection{Brand awareness}

Kesadaran merek (brand awareness) adalah kesanggupan seorang calon pembeli untuk mengetahui atau mengingat kembali suatu bentuk, merek, simbol atau logo dari produk tersebut. Maka semakin banyak orang yang teringat akan sebuah merek atau produk pada saat mendengar suatu kata, maka semakin baik brand awareness merek atau produk tersebut. Brand awareness penting bagi produsen, karena konsumen akan cenderung membeli produk yang sudah dikenal atau diingat olehnya (Severi \& Ling, 2013). Dapat disimpulkan bahwa menciptakan kesadaran merek (brand awareness) merupakan langkah penting perusahaan untuk mempromosikan produk dan jasanya. Kesadaran merek (brand awareness) terdiri dari brand recognition dan brand recall performance. Brand recognition adalah kesanggupan seorang calon pembeli untuk mengenali merek yang ditawarkan perusahaan, sedangkan brand recall adalah kesanggupan seorang calon pembeli untuk retrieve merek saat mengingat kategori produk.

\subsection{Brand loyalty}

Loyalitas merek (brand loyalty) adalah keadaan komitmen dimana pelanggan memilih melanjutkan penggunaan dari merek atau membeli kembali merek yang sama. Loyalitas merek sama artinya dengan keputusan pembelian berdasarkan motivasi yang kuat untuk membeli kembali. Dengan demikian, loyalitas merek secara langsung dipengaruhi oleh kepuasan atau ketidakpuasan pelanggan terhadap merek tertentu (Hill, 2014). Severi et al., (2013) memberikan pengertian bahwa Brand loyalty merupakan salah satu indikator penting dari brand equity. Bila loyalitas pelanggan terhadap suatu merek meningkat, kerentanan kelompok pelanggan tersebut dari ancaman dan serangan merek produk pesaing dapat dikurangi. Brand loyalty merupakan salah satu indikator inti dari brand equity yang jelas terkait dengan peluang penjualan, yang berarti pula jaminan perolehan laba perusahaan di masa mendatang. Brand loyalty juga meningkatkan kepuasan pelanggan.

Indikator brand loyalty adalah (1) Switcher; konsumen yang berada pada tingkat loyalitas ini dikatakan sebagai konsumen yang berada pada tingkat paling dasar. (2) Habitual Buyer; Pembelian yang berada pada tingkat loyalitas ini dapat dikategorikan sebagai pembeli yang puas dengan merek produk yang dikonsumsinya atau setidaknya mereka tidak mengalami ketidakpuasan dalam mengkonsumsi merek produk tersebut. (3) Satisfied Buyer; pada tingkatan 
ini, pembeli masuk dalam kategori puas bila mereka mengkonsumsi merek tersebut. (4) Like the Brand; pembeli yang masuk dalam kategori ini merupakan pembeli yang sungguh sungguh menyukai suatu merek. Pada tingkatan ini dapat dijumpai perasaan emosional yang terkait pada merek. (5) Commited Buyer; pada tahap ini konsumen dianggap sebagai seorang pembeli yang setia, dimana mereka memiliki suatu kebanggaan menjadi pengguna merek dan mereka menganggap bahwa merek tersebut menjadi sangat penting bagi mereka baik dipandang dari segi fungsinya maupun dipandang sebagai suatu ekspresi mengenai siapa sebenarnya mereka.

Dapat disimpulkan bahwa brand loyalty (loyalitas merek) merupakan suatu ukuran mengenai keterkaitan konsumen terhadap suatu merek, dimana ukuran ini mampu memberikan gambaran mengenai mungkin tidaknya konsumen beralih ke merek atau produk yang lain.

\subsection{Harga}

\subsubsection{Pengertian Harga}

Menurut Kotler dan Amstrong (2001) harga adalah sejumlah uang yang dibebankan atas suatu produk, atau jumlah dari nilai yang ditukar konsumen atas manfaat - manfaat karena memiliki atau menggunakan produk tersebut ${ }^{1}$. Harga adalah satuan moneter atau ukuran lainnya (termasuk barang dan jasa) yang ditukarkan agar memperoleh hak kepemilikan atau penggunaan suatu barang atau jasa. Sementara menurut Dharmesta dan Irawan (2005), harga adalah sejumlah uang (ditambah beberapa produk kalau mungkin) yang dibutuhkan untuk mendapatkan sejumlah kombinasi dari produk dan pelayanannya. Tjiptono (2007) mendefinisikan harga dari dua sudut pandang, yaitu dari sudut pandang pemasaran, harga merupakan satuan moneter atau ukuran lainnya (termasuk barang dan jasa lainnya) yang ditukarkan agar memperoleh hak kepemilikan atau penggunaan suatu barang atau jasa. Sementara itu, dari sudut pandang konsumen, harga seringkali digunakan sebagai indikator nilai bilamana harga tersebut dihubungkan dengan manfaat yang dirasakan atas suatu barang atau jasa. Nilai dapat didefinisikan sebagai rasio antara manfaat yang dirasakan terhadap harga.

Stanton (2001) menyatakan harga adalah sejumlah nilai yang ditukarkan konsumen dengan manfaat dari memiliki dan menggunakan produk atau jasa yang ditetapkan oleh pembeli atau penjual untuk suatu harga yang sama terhadap semua pembeli. Sementara Ferdinand (2000) menjelaskan bahwa harga merupakan salah satu variabel penting dalam pemasaran, dimana harga dapat mempengaruhi pelanggan dalam mengambil keputusan untuk membeli suatu produk, karena berbagai alasan. Alasan ekonomis akan menunjukkan bahwa harga yang rendah atau harga yang selalu berkompetisi merupakan salah satu pemicu penting untuk meningkatkan kinerja pemasaran, tetapi alasan psikologis dapat menunjukkan bahwa harga

${ }^{1}$ Philip Kotler dan Gary Amstrong, Manajemen Pemasaran (Jakarta : Ghalia Indonesia, 2003) hal 430 
justru merupakan indikator kualitas dan karena itu dirancang sebagai salah satu instrumen penjualan sekaligus sebagai instrumen kompetisi yang menentukan.

\subsection{Customer Satisfaction}

\subsubsection{Pengertian Customer Satisfaction (Kepuasan Pelanggan)}

Secara tradisional pengertian kepuasan atau ketidakpuasan pelanggan merupakan perbedaan antara harapan dan kinerja yang dirasakan (perceived performance). Pengertian ini didasarkan pada "disconfirmation paradigma" dari Oliver (1980) yaitu kinerja pemberi jasa sekurang-kurangnya sama dengan yang diharapkan pelanggan. Kepuasan pelanggan ditentukan oleh dua variabel kognitif yakni harapan pada saat sebelum pembelian (prepurchase expectation) yaitu keyakinan tentang kinerja yang diantisipasi dari suatu produk jasa dan "disconfirmation" yaitu perbedaan antara prapembelian dan persepsi dari purna pembelian (post purchase prescription)".

Day dalam Tjiptono (1998) mengatakan: "Kepuasan atau ketidakpuasan pelanggan adalah respon pelanggan terhadap evaluasi ketidaksesuaian (disconfirmation) yang dirasakan antara harapan sebelumnya atau harapan kinerja lainnya dan kinerja aktual produk yang dirasakan setelah pemakaiannya.” Kepuasan pelanggan menurut Zeithaml, Bitner dan Dwayne (2009) adalah penilaian pelanggan atas produk ataupun jasa dalam hal menilai apakah produk atau jasa tersebut telah memenuhi kebutuhan dan ekspektasi pelanggan.

Menurut Kotler dan Keller (2009), kepuasan merupakan perasaan senang atau kecewa yang dihasilkan dari perbandingan performance produk terhadap ekspektasi mereka. Jika performance tidak memenuhi ekspektasi, maka pelanggan menjadi tidak puas. Jika performance memenuhi ekspektasi, maka pelanggan menjadi puas. Jika performance melebihi ekspektasi, maka pelanggan merasa sangat puas.

\section{METODOLOGI}

\subsection{Populasi dan Sampel Penelitian}

Populasi penelitian ini adalah semua konsumen produk PT. Jico Agung di Jakarta Timur. Pemilihan sampel menggunakan teknik purposive sampling yaitu teknik penentuan sampel dengan pertimbangan tertentu (Sugiyono, 2007). Kriteria penentuan sampel adalah sebagai berikut:

1. Seluruh konsumen produk PT. Jico Agung di Jakarta Timur

2. Konsumen produk PT. Jico Agung di wilayah Kelurahan Utan Kayu Utara,

Jakarta Timur. Mayoritas responden adalah ibu rumah tangga di lingkungan RT.013 dan RT.014.

Jumlah anggota sampel atau besarnya sampel (sample size) ditetapkan responden dengan pertimbangan waktu, tenaga dan biaya. Berdasarkan teori Gay dan Diehl 
(1992) yang mengatakan bahwa ukuran sampel untuk kepentingan korelasional dibutuhkan minimal sebanyak 30 subyek penelitian.

\subsection{Lokasi dan Waktu Penelitian}

Tempat penelitian dilaksanakan pada PT. Jico Agung, yang berlokasi di

Jl. Perintis

Kemerdekaan No.1-3 Pulo Gadung, Jakarta Timur. Penelitian ini dilakukan dalam waktu selama 3 (tiga) bulan, yaitu Agustus-Oktober 2019.

\subsection{Sifat dan Jenis Penelitian}

Dalam penelitian ini menggunakan penelitian asosiatif, untuk mengetahui hubungan dua variabel atau lebih (Sugiyono, 2005).

\subsection{Definisi Operasionalisasi Variabel}

Tabel 1. Variabel, Dimensi, Indikator

\begin{tabular}{|c|c|c|c|}
\hline $\begin{array}{ll}S & \text { Variabel }\end{array}$ & Dimensi & Indikator & $\begin{array}{c}\text { No. } \\
\text { Pertanyaan }\end{array}$ \\
\hline $\begin{array}{l}\text { Brand } \\
\text { Awareness (X1) }\end{array}$ & $\begin{array}{l}\text { Brand recognition } \\
\text { Brand recall }\end{array}$ & $\begin{array}{l}\text { Mengenali merek } \\
\text { Mengingat/retrieve merek saat mengingat kategori } \\
\text { produk } \\
\text { Mampu membedakannya dengan produk lain }\end{array}$ & $\begin{array}{l}1 \\
2 \\
3 \\
4 \\
5\end{array}$ \\
\hline \begin{tabular}{|l} 
Brand \\
Loyalty \\
(X2)
\end{tabular} & $\begin{array}{ll}> & \text { Switcher } \\
> & \text { Habitual } \\
& \text { Buyer } \\
> & \text { Satisfied Buyer } \\
> & \text { Like the Brand } \\
> & \text { Commited Buyer }\end{array}$ & $\begin{array}{ll}> & \text { Membeli produk dan tidak beralih } \\
> & \text { Produk biasa dikonsumsi keluarga } \\
\text { lain } & \text { Puas bila mengkonsumsi produk bukan merek } \\
> & \text { Sungguh }- \text { sungguh menyukai produk } \\
\text { fungsi } & \text { Produk sangat penting bila dilihat dari segi }\end{array}$ & $\begin{array}{l}1 \\
2 \\
3 \\
4 \\
5 \\
6\end{array}$ \\
\hline $\begin{array}{l}\text { Harga } \\
\text { (X3) }\end{array}$ & $\begin{array}{r}\text { Faktor } \\
\text { Eksternal } \\
\text { Faktor } \\
\text { Internal }\end{array}$ & $\begin{array}{l}\text { Sifat pasar } \\
\text { Pengaruh permintaan terhadap harga } \\
\text { Tinggi rendahnya tawaran pesaing } \\
\text { Kesesuaian harga produk dengan kualitas } \\
\text { Harga terjangkau } \\
\text { Semakin rendah harga produk akan dibeli }\end{array}$ & $\begin{array}{l}1 \\
2 \\
3 \\
4 \\
5\end{array}$ \\
\hline $\begin{array}{l}\text { Customer } \\
\text { Satisfaction } \\
\text { (Kepuasan } \\
\text { Pelanggan) } \\
\text { (Y) }\end{array}$ & $\begin{array}{|lr|}\text { Perbandingan } & \text { kinerja } \\
\text { produk } & \text { terhadap } \\
\text { ekspektasi } & \end{array}$ & $\begin{array}{l}>\text { Membeli produk karena menyukai rasanya } \\
\text { secara konsisten } \\
>\text { Mampu memenuhi kebutuhan pangan } \\
>\text { Kualitas produk sesuai keinginan } \\
>\text { Produk pilihan yang tepat untuk dikonsumsi } \\
>\text { Produk sesuai dengan harapan pelanggan } \\
>\text { Puas atas produk setelah konsumsi }\end{array}$ & $\begin{array}{l}1 \\
2 \\
3 \\
4 \\
5 \\
6\end{array}$ \\
\hline
\end{tabular}

sumber : dirangkum oleh peneliti (2019) 


\subsection{Metode Pengumpulan Data}

Dalam menyusun penelitian ini digunakan 2 (dua) macam data, yaitu:

a. Data Primer, data yang didapat melalui observasi, wawancara dan kuesioner.

b. Data sekunder, data yang diperoleh secara tidak langsung melalui literature yang telah ada seperti majalah, surat kabar, dan internet mengenai masalah yang relevan.

Teknik pengumpulan data yang digunakan dalam penelitian dibagi menjadi 2 (dua), yaitu:

a. Studi Lapangan (field research) dengan cara mengumpulkan data langsung dari lokasi penelitian, yaitu pada saat kegiatan Posyandu RW.07.

b. Studi Kepustakaan (library research) mengumpulkan data teoritis yang menjadi landasan teori untuk melaksanakan penelitian ini dengan cara mempelajari berbagai buku atau literatur yang berhubungan dengan penyusunan penelitian ini.

\section{HASIL PENELITIAN DAN PEMBAHASAN}

\subsection{Karakteristik Responden}

Responden penelitian ini adalah warga RW.07 Utan Kayu Utara, Jakarta Timur yang menjadi konsumen tepung bakwan Mamasuka. Kuesioner yang terkumpul sejumlah 30 . Karakteristik responden berdasarkan data demografi adalah sebagai berikut:

\subsubsection{Berdasarkan Jenis Kelamin}

Penulis telah berasumsi bahwa mayoritas konsumen tepung bakwan Mamasuka adalah perempuan yakni para ibu, sesuai hasil survey di lapangan.

Tabel 2 . Responden Berdasarkan Jenis Kelamin

\begin{tabular}{cll}
\hline Jenis Kelamin & Frekuensi & Persentase (\%) \\
\hline Laki - Laki & 0 & 0 \\
Perempuan & 30 & 100 \\
Jumah & 30 & 100
\end{tabular}

Sumber: Data Kuisioner

Berdasarkan tabel di atas, dapat dilihat bahwa mayoritas konsumen tepung bakwan Mamasuka adalah perempuan karena memang kegiatan memasak umumnya dilakukan para ibuibu.

\subsubsection{Berdasarkan Usia}


Tabel 3. Responden Berdasarkan Usia

\begin{tabular}{|c|c|c|}
\hline $\begin{array}{l}\text { Usia responden } \\
\text { (tahun) }\end{array}$ & $\begin{array}{l}\text { Jumlah } \\
\text { responden }\end{array}$ & $\begin{array}{l}\text { Frekuensi } \\
\text { Persentase (\%) }\end{array}$ \\
\hline$<31$ & 7 & 23,3 \\
\hline $31-35$ & 7 & 23,3 \\
\hline $36-40$ & 10 & 33,3 \\
\hline$>40$ & 6 & 20,0 \\
\hline Jumlah & 30 & 100,0 \\
\hline
\end{tabular}

Berdasarkan tabel di atas, dapat dilihat bahwa usia responden tertinggi pada kisaran 3640 tahun yakni sebanyak 10 orang (33.3\%) lalu kemudian diikuti oleh kisaran usia 31 - 35 dan usia $<31$ tahun masing-masing sebanyak 7 orang $(23,4 \%)$. Sedangkan sisanya yang berusia di atas 40 tahun yakni 6 orang (20,0\%). Jadi dapat disimpulkan bahwa mayoritas responden adalah ibu-ibu di lingkungan RT.013 dan RT.014 RW.07 Utan Kayu Utara, Jakarta Timur.

\subsubsection{Berdasarkan Pendidikan Terakhir}

Tabel 4. Responden Berdasarkan Pendidikan Terakhir

\begin{tabular}{lcc}
\hline Pendidikan Terakhir & Frekuensi & Persentase (\%) \\
\hline SD & 2 & 6,7 \\
SMP & 4 & 13,3 \\
SMA & 13 & 43,3 \\
D3 & 5 & 16,7 \\
Sarjana & 6 & 20,0 \\
Jumlah & 30 & 100,0
\end{tabular}

Sumber: Data Kuisioner

Dari segi pendidikan, dapat dilihat bahwa mayoritas responden berpendidikan terakhir SMA yakni sebanyak 13 orang (43,3\%). Di urutan kedua berpendidikan sarjana yakni 6 orang (20\%), kemudian D3 sebanyak 5 orang (16,7\%), SMP sebanyak 4 orang (13,3\%) dan SD sebanyak 2 orang $(6,7 \%)$

\subsubsection{Berdasarkan Pekerjaan Responden}

Tabel 5. Pekerjaan Responden

\begin{tabular}{lcc}
\hline Pekerjaan & Frekuensi & Persentase (\%) \\
\hline Ibu rumah tangga & 21 & 70 \\
Pegawai Negeri/Guru & 3 & 10 \\
Pegawai swasta & 5 & 16,6 \\
Wiraswasta/Wirausaha & 1 & 3,3 \\
Jumlah & 30 & 100
\end{tabular}

Sumber: Data Kuisioner 
Berdasarkan data yang diperoleh, mayoritas sebagai ibu rumah tangga (21 orang). Sedangkan sebanyak 5 orang $(16,6 \%)$ adalah pegawai swasta, 3 orang (10\%) adalah Pegawai Negeri/Guru dan 1 orang adalah wiraswasta, yakni membuka warung makan.

\subsubsection{Produk Mama Suka (Jico Agung) yang sering dibeli Responden}

Tabel 6 . Produk Mama Suka (Jico Agung) yang sering dibeli Responden

\begin{tabular}{lll}
\hline Produk & Frekuensi & $\begin{array}{l}\text { Persentase } \\
(\%)\end{array}$ \\
\hline Tepung Bumbu Serbaguna & 1 & 3,3 \\
Tepung Bakwan & 16 & 53,3 \\
Tepung Kentucky & 8 & 26,7 \\
Tepung bumbu Ayam Goreng & 2 & 6,7 \\
Lainnya & 3 &
\end{tabular}

\section{Sumber: Data Kuisioner}

Berdasarkan tabel di atas, dapat dilihat bahwa tepung bakwan Mamasuka diingat oleh responden ketika diminta untuk menyebutkan jenis tepung.

\section{HASIL PEMBAHASAN}

\subsection{Uji Kualitas Data}

Data yang dikumpulkan dari kuesioner merupakan sejumlah pertanyaan dan pernyataan yang mewakili empat variabel yang diteliti yaitu variabel brand awareness (X1), brand loyalty (X2) and harga (X3) terhadap kepuasan konsumen (Y). Penilaian keempat instrumen tersebut menggunakan skala Likert dengan skala jawaban 1, 2, 3, 4 dan 5 untuk setiap item pernyataan yang diajukan. Sebagian besar responden menjawab setuju dan sangat setuju terhadap butirbutir pernyataan. Berdasarkan hasil uji validitas instrumen dari keempat variabel penelitian menunjukan bahwa seluruh butir pernyataan valid, karena nilai $\mathrm{r}$ hitung (korelasi Product Moment Carl Pearson) lebih besar dari $\quad \mathrm{r}$ tabel dan atau tingkat Signifikansi $<0,05$. Uji reliabilitas dengan uji statistik Alpha Cronbach (Cronbach's Alpha) menunjukan keempat data varibel adalah reliable karena nilai koefisien korelasi $r$ Alpha Cronbach lebih besar dari nilai $r$ tabel atau nilai r-hitung lebih besar dari r-tabel.

\subsection{Koefisien Korelasi $(\mathbf{R})$ dan Koefisien Determinasi $\left(\mathbf{R}^{2}\right)$ Berganda}


Tabel 7. Koefisien Determinasi $\left(\mathrm{R}^{2}\right)$ Berganda

Model Summary

\begin{tabular}{|l|c|c|c|c|}
\hline Model & $\mathrm{R}$ & R Square & $\begin{array}{c}\text { Adjusted R } \\
\text { Square }\end{array}$ & $\begin{array}{c}\text { Std. Error of the } \\
\text { Estimate }\end{array}$ \\
\hline 1 & .848 & 0.720 & 0.687 & 1.311 \\
\hline
\end{tabular}

a. Predictors: (Constant), brand awareness, brand loyalty, harga

Sumber : Output Data Pengolahan SPSS 25

Pada Tabel 7 diketahui nilai koefisien korelasi berganda sebesar $0,848(R=0,848)$ dan koefisien determinasi yang dilihat dari nilai $A d j . R^{2}$ adalah 0,687 artinya $68,7 \%$ variasi dari variabel dependen kepuasan pelangan dapat diprediksi dari kombinasi seluruh variabel independen yaitu brand awareness, brand loyalty, dan harga. Sisanya 31,3\% dipengaruhi oleh faktor-faktor lain yang tidak diteliti.

\subsection{Analisis Regresi Linear Berganda}

Analisis regresi linear berganda untuk mengetahui seberapa besar pengaruh variabel independen X (brand awareness, brand loyalty,dan harga) secara simultan terhadap variabel dependen $\mathrm{Y}$ (kepuasan pelangan). Dengan melihat hasil perhitungan nilai koefisien beta (Unstandardized Coefficients B) pada Tabel 8 berikut maka dapat disusun persamaan regresi linear berganda sebagai berikut:

$$
\hat{\mathbf{Y}}=0,026+0,360 \mathrm{X} 1+0,397 \mathrm{X} 2+\mathbf{0 , 2 3 4} \mathrm{X3} \text {. }
$$

Tabel 8. Regresi Linier Berganda variabel brand awareness (X1), brand loyalty $(\mathrm{X} 2)$ dan harga $(\mathrm{X} 3)$ terhadap kepuasan pelangan $(\mathrm{Y})$

\begin{tabular}{|c|c|c|c|c|c|c|}
\hline \multicolumn{7}{|c|}{ Coefficients $^{\mathrm{a}}$} \\
\hline \multirow{3}{*}{\multicolumn{2}{|c|}{ Model }} & \multirow{2}{*}{\multicolumn{2}{|c|}{$\begin{array}{l}\text { Unstandardized } \\
\text { Coefficients }\end{array}$}} & \multirow{2}{*}{$\begin{array}{l}\text { Standardized } \\
\text { Coefficients }\end{array}$} & \multirow{3}{*}{$\mathrm{t}$} & \multirow{3}{*}{ Sig. } \\
\hline & & & & & & \\
\hline & & $\mathrm{B}$ & Std. Error & Beta & & \\
\hline \multirow[t]{4}{*}{1} & (Constant) & .026 & 2.591 & & .010 & .992 \\
\hline & brand awareness & .360 & .160 & .329 & 2.245 & .034 \\
\hline & brand loyalty & .397 & .182 & .360 & 2.178 & .039 \\
\hline & harga & .234 & .113 & .286 & 2.061 & .049 \\
\hline
\end{tabular}

a. Dependent Variable: kepuasan pelangan

Sumber : Output Data Pengolahan SPSS 25

Koefisien regresi variabel brand awareness $\left(B_{l}\right)$ sebesar 0,360 bertanda positif, hal ini berarti bahwa setiap perubahan satu nilai pada variabel brand awareness sementara variabel lainnya tetap maka variabel kepuasan pelanggan akan mengalami perubahan sebesar 0,360 
dengan arah yang sama. Brand awareness yang tinggi akan meningkatkan kepuasan pelanggan lebih besar pada produk tepung bakwan mamasuka.

Koefisien regresi variabel brand loyalty $\left(B_{2}\right)$ sebesar 0,397 bertanda positif, hal ini berarti bahwa setiap perubahan satu nilai pada variabel brand loyalty sementara variabel lainnya tetap maka variabel kepuasan pelanggan akan mengalami perubahan sebesar 0,397 dengan arah yang sama. Brand loyalty yang tinggi akan meningkatkan kepuasan pelanggan lebih besar pada produk tepung bakwan mamasuka.

Koefisien regresi variabel harga $\left(B_{3}\right)$ sebesar 0,234 bertanda positif, hal ini berarti bahwa setiap perubahan satu nilai pada variabel harga sementara variabel lainnya tetap maka variabel kepuasan pelanggan akan mengalami perubahan sebesar 0,234 dengan arah yang sama. Harga yang sesuai dengan harapan pelanggan akan meningkatkan kepuasan pelanggan lebih besar pada produk tepung bakwan mamasuka.

\section{Uji t (Uji Parsial)}

Pengujian hipotesis pada penelitian ini menggunakan hasil dari uji $\mathrm{t}$ yang memperlihatkan seberapa jauh pengaruh satu variabel bebas (brand awareness, brand loyalty, harga) secara parsial (individual) dalam menjelaskan variasi variabel terikat (kepuasan pelangan). Uji t membandingkan hasil nilai probabilitas signifikansi pada Tabel 8 dengan tingkat signifikansi sebesar $5 \%(\alpha=0,05)$, yang dapat disimpulkan sebagai berikut:

\section{Hasil pengujian Hipotesis 1:}

Nilai signifikansi variabel brand awareness sebesar 0,001 < alpha 0,05. Maka $\mathrm{Ho}_{1}$ ditolak, artinya terdapat pengaruh brand awareness terhadap kepuasan pelanggan produk tepung bakwan mamasuka.

\section{Hasil pengujian Hipotesis 2:}

Nilai signifikansi variabel brand loyalty sebesar $0.000<$ alpha 0.05 . Maka $\mathrm{Ho}_{2}$ ditolak, artinya terdapat pengaruh variabel independen brand loyalty terhadap variabel dependen kepuasan pelanggan produk tepung bakwan mamasuka.

\section{Hasil pengujian Hipotesis 3:}

Nilai signifikansi variabel harga sebesar $0.004>$ alpha 0.05 . Maka $\mathrm{Ho}_{4}$ ditolak, artinya terdapat pengaruh variabel independen harga terhadap variabel dependen kepuasan pelanggan produk tepung bakwan mamasuka.

\section{Uji Signifikasi Simultan (Uji F)}

Bentuk persamaan regresi linear berganda diperkuat dengan uji $F$ ( $F$ test) untuk mengetahui apakah semua variabel independen (brand awareness, brand loyalty, harga) yang dimasukkan dalam model regresi mempunyai pengaruh terhadap variabel dependen (kepuasan pelangan) secara bersama-sama (simultan). Dasar pengambilan keputusan dengan 
membandingkan nilai $\mathrm{F}$ hasil perhitungan $\left(\mathrm{F}_{\text {hitung }}\right)$ dengan nilai $\mathrm{F}$ dari tabel $\left(\mathrm{F}_{\text {tabel }}\right)$ pada $\alpha$ dan nilai degree of freedom tertentu $(\mathrm{v} 1=\mathrm{k}$ dan $\mathrm{v} 2=\mathrm{n}-\mathrm{k}-1)$.

Tabel 10. Uji F (ANNOVA Test)

\begin{tabular}{|c|c|c|c|c|c|c|}
\hline \multicolumn{7}{|c|}{ ANOVA $^{b}$} \\
\hline \multirow[b]{2}{*}{ Model } & & \multicolumn{5}{|l|}{ Sum of } \\
\hline & & Squares & $\mathrm{df}$ & Mean Square & $\mathrm{F}$ & Sig. \\
\hline \multirow[t]{3}{*}{1} & Regression & 114.811 & 3 & 38.270 & 22.266 & $.000^{a}$ \\
\hline & Residual & 44.689 & 26 & 1.719 & & \\
\hline & Total & 159.500 & 29 & & & \\
\hline
\end{tabular}

a. Predictors: (Constant), brand awareness, brand loyalty, harga

b. Dependent Variable: Kepuasan pelanggan

Sumber : Output Data Pengolahan SPSS 25

Pengujian serentak menghasilkan nilai F statistic sebesar 22.266 dengan nilai sig. sebesar $0.000<0.05$ dimana Ho ditolak yang artinya secara serentak seluruh variabel independen yaitu brand awareness, brand loyalty, harga berpengaruh secara signifikan terhadap variabel dependen kepuasan pelanggan produk tepung bakwan mamasuka.

\section{SIMPULAN DAN SARAN}

\subsection{Simpulan}

Berdasarkan uraian hasil penelitian mengenai pengaruh brand awareness (X1), brand loyalty (X2) dan harga (X3) terhadap kepuasan konsumen tepung bakwan mamasuka menunjukan bahwa:

1. Brand awareness berpengaruh positif terhadap kepuasan konsumen. Hal ini menjelaskan bahwa semakin baik brand awareness, sementara variabel lainnya tetap maka variabel kepuasan konsumen akan mengalami kenaikan. Brand awareness berarti konsumen mengetahui dan mengingat semua atribut produk/jasa.

2. Brand loyalty berpengaruh positif terhadap kepuasan konsumen. Hal ini menjelaskan bahwa semakin baik Brand loyalty, sementara variabel lainnya tetap maka variabel kepuasan konsumen akan mengalami kenaikan. Hal ini dikarenakan brand loyalty merupakan komitmen penuh dari konsumen untuk melakukan pembelian berulang produk/jasa yang sama, merekomendasikan kepada orang lain dan menceritakan pengalaman yang positif mengenai brand tersebut.

3. Harga berpengaruh positif terhadap kepuasan konsumen. Hal ini menjelaskan bahwa semakin baik kebijakan harga, sementara variabel lainnya tetap maka variabel kepuasan konsumen akan mengalami kenaikan. Hal ini dikarenakan, harga yang ditawarkan perusahaan masih menjadi pertimbangan penting oleh konsumen. Jadi kebijakan harga harus sesuai dengan kemampuan daya beli konsumen. 


\subsection{Saran}

Berdasarkan hasil penelitian ini, saran yang dapat dikemukan peneliti adalah:

1. Tepung bakwan mamasuka harus tetap menjaga posisinya di pasar sebagai market leader dan terus melakukan inovasi baru terutama terkait kualitas produk dengan tetap menjaga stabilitas harga, agar tidak kalah bersaing dengan produk sejenis di pasar melihat banyaknya perusahaan yang masuk pada pasar produk yang sejenis sehingga persaingan semakin tinggi.

2. PT. Jico Agung disarankan untuk meningkatkan kualitas, varian dan desain produk serta memberikan harga yang kompetitif untuk meningkatkan minat beli konsumen ditengah kompetitor yang semakin bertambah. Perusahaan perlu secara intens mengevaluasi kebutuhan dan keinginan konsumen atau pasar agar dapat meningkatkan keputusan pembelian di masa mendatang sehingga tercapat kepuasan konsumen.

3. Penelitian lebih lanjut dapat dilakukan dengan menambah jumlah responden dan variabel lain yang tidak dimasukan dalam penelitian ini dikarenakan masih banyak faktor-faktor lain yang mempengaruhi perilaku pembelian konsumen, dan mengembangkan penelitian pada jenis perusahaan lain. Variabel dependen lain yang dapat digunakan pada penelitian selanjutnya antara lain: persepsi kualitas (perceived quality), citra merek (brand image), WOM (Worth of mouth), Ekuitas merek (Brand equity). Sedangkan variabel independen lain yang dapat digunakan pada penelitian selanjutnya antara lain: Keputusan pembelian (Purchased Decision)/Minat beli, Customer loyalty

\section{DAFTAR PUSTAKA}

Ali Hussein. (2012). Customer's satisfaction and brand awareness, Case: Bulsho Cooperative, Finland. University of Applied Science.

Asri Layyinatul. (2015). Pengaruh Brand Awareness, Brand Trust dan Kepuasan Terhadap Loyalitas (Studi Kasus BNI Syariah Kantor Cabang Yogyakarta). UIN Sunan Kalijaga Yogyakarta.

Bilal, Atif \& Faiza Majid Malik. (2014). "Impact of Brand Equity \& Brand Awaraness on Customer's Satisfaction". International Journal of Modern Management \& Foresight, Vol.1.

Ghozali, Imam. (2005). Aplikasi Analisis Multivariate dengan Program SPSS., Semarang : Badan Penerbit Universitas Diponegoro. 
Malik, Ehsan; Mudasar Ghafoor \& Hafiz Kashif. (2012). Impact of Brand Image, Service Quality and Price on Customer Satisfaction in Pakistan Telecommunication Sector. International Journal of Business and Social Science Vol. 3 No. 23; December 2012

Noviana. 2013. Pengaruh Perceived Quality dan Brand Loyalty Terhadap Purchased Decision Pada BLITZMEGAPLEX (Studi Kasus: Pengunjung BLITZMEGAPLEX Central Park Pada Periode MEI 2013). Universitas Bina Nusantara.

Selly Pratama, Miken. (2017). Analisis Pengaruh Kesadaran Merek, Persepsi Kualitas dan Loyalitas Merek Terhadap Kepuasan Konsumen Pada Produk Private Label Indomaret. Universitas Muhammadiyah Surakarta.

Sugiyono, 2009, Metode Penelitian Kuantitatif, Kualitatif dan R\&D, Alfabeta Bandung..

Tjiptono, Fandy. (2002). Strategi Pemasaran. Yogyakarta : Andy Offset.

Tjandrasa, Benny B. (2006). "Potensi Keuntungan Private Label Serta proses Pemilihan

Yunitasari, Herma, dan Ahyar Yuniawan. (2006). "Analisis Pengaruh Kesadaran Merek, Persepsi Kualitas, dan Loyalitas Merek Terhadap Nilai Pelanggan Mobil Merek Toyota”, Jurnal Studi Manajemen dan Organisasi. Vol. 3, No. 2. 